\title{
OBJEÇÕES À CRÍTICA NEOINSTITUCIONALISTA: a proposta teórica de Ronald Dworkin pressupõe discricionariedade para o juiz criar regras jurídicas
}

\author{
Vítor Oliveira Rocha Fontes ${ }^{1}$
}

\section{RESUMO}

Este artigo apresenta reflexões acerca da crítica neoinstitucionalista do processo de que a teoria do direito com integridade de Ronald Dworkin pressupõe ao juiz discricionariedade para criar regras jurídicas pelo manejo de princípios morais. O estudo é relevante porque o art. 926 do Código de Processo Civil refere-se expressamente à integridade dworkiniana, exigindo-se, assim, uma adequada compreensão do direito como integridade, o qual nega ao juiz a discricionariedade apontada pela teoria neoinstitucionalista do processo. $O$ trabalho foi desenvolvido por meio de pesquisa bibliográfica a partir da vertente jurídico-teórica e do procedimento jurídico-compreensivo.

Palavras-chave: Direito como integridade. Ronald Dworkin. Discricionariedade. Teoria neoinstitucionalista.

\begin{abstract}
This paper presents reflections on the neoinstitutionalist critique of the process that Ronald Dworkin 's theory of law with integrity presupposes to the judge discretion to create legal rules for the management of moral principles. The study is relevant because the art. 926 of the Code of Civil Procedure expressly refers to Dworkinian integrity, thus requiring an adequate understanding of the law as integrity, which, duly understood, refutes the criticism presented by the neoinstitutionalist theory of the process. The work was developed from the juridicaltheoretical side and the legal-understanding procedure.
\end{abstract}

Keywords: Law as integrity. Ronald Dworkin. Legal discretion. Neoinstitutionalist theory.

\footnotetext{
${ }^{1}$ Mestrando em Direito pela FUMEC (Fundação Mineira de Educação e Cultura). Oficial da Polícia Militar de Minas Gerais. Currículo Lattes: http://lattes.cnpq.br/9036500161407581. E-mail: vitorfontes @ fumec.edu.br

Rev. De Teorias Da Justiça, Da Decisão E Da Argumentação Jurídica | e-ISSN: 2525-9644| Goiânia| v. 5 | n. 1 | p. 39-
} 


\section{INTRODUÇÃO}

O escopo deste artigo é apresentar reflexões acerca da crítica da teoria neoinstitucionalista do processo de que a proposta teórica de Ronald Dworkin pressupõe ao juiz discricionariedade para criar regras jurídicas pelo manejo de princípios morais.

O estudo é relevante pois a Lei n. 13.105, de 16 março de 2015, positivou no art. 926 o dever de os tribunais manter a 'integridade' de sua jurisprudência, termo prescrito, segundo Theodoro Júnior et al (2016), com a finalidade específica de remeter os interpretes do direito a teoria dworkiniana do direito como integridade. E compreender o instituto permitirá a correta interpretação e aplicação do dispositivo normativo.

Para tanto, este estudo de caso, com abordagem jurídico-compreensiva na vertente jurídico-teórica, apresentará a partir da seção 2 os principais elementos da teoria dworkiniana. Na seção 3, apresentará a crítica neoinstitucionalista, para, ao final, verificar o grau de procedência das objeções à teoria do direito como integridade no processo judicial.

\section{FUNDAMENTOS TEÓRICOS BÁSICOS}

O principal desiderato da teoria do direito como integridade é dar legitimidade aos fundamentos do Direito, nesse sentido, Brina (2016), Pedron (2013) e Macedo Júnior (2013) explicam que Dworkin propõe um modelo ético-jurídico-filosófico abrangente de justificação moral das concepções sobre 'o que é o Direito' de maneira a tornar legítimo o exercício de poder da comunidade político-jurídica.

A problemática em torno dos critérios utilizados para se atribuir legitimidade ao mundo jurídico é posta por Dworkin (1999) a partir da indagação do porquê as pessoas têm o dever de obedecer ao direito:

O enigma da legitimidade [...] Os cidadãos têm obrigações morais genuínas unicamente em virtude do direito? $\mathrm{O}$ fato de que um legislativo tenha aprovado alguma exigência oferece aos cidadãos alguma razão ao mesmo tempo moral e prática para obedecer? (DWORKIN, 1999, p. 253, grifo do autor).

A partir disso, o autor desconstruirá as justificações contratualistas ${ }^{2}$, as justificações

\footnotetext{
${ }^{2}$ Refere-se à ideia que a legitimidade de se cumprir as obrigações e prerrogativas decorrentes do Direto teria origem no contrato ancestral. Aqui se insere as propostas de Rosseau, Hobbes e derivações (CATTONI DE OLIVEIRA, 2016). E também a idéia que, tendo as pessoas recebido benefícios decorrentes da organização político-estatal, elas terão que aceitar as regras e obrigações decorrentes desse modelo, como propõe John Rawls. (FURQUIM, 2010).

Rev. De Teorias Da Justiça, Da Decisão E Da Argumentação Jurídica | e-ISSN: 2525-9644| Goiânia| v. 5 | n. 1 | p. 39-
} 
decisionistas $^{3}$ e as justificações de auto-retribuição ${ }^{4}$, ao fazer as seguintes objeções: (1) qual a legitimidade de uma obrigação originária de uma relação que não se tem a oportunidade de escolher fazer, ou não, parte dela? (2) como demonstrar que a organização política a que se pertence trouxe melhorias para o indivíduo se não é possível comparar como seria a vida desse indivíduo sem essa organização política? (3) como esperar a justificação do direito a partir de uma reciprocidade afetiva - respeitar o outro por ser seu semelhante - se é impossível haver laços emocionais entre todas as pessoas de uma comunidade ampla? (4) como legitimar o reconhecimento de obrigações jurídicas a partir da comunhão de elementos étnicos, religiosos ou nacionalistas, se isso implica excluir da comunidade política aqueles que não comungam com esses elementos - e, assim, fomentar a discriminação? (5) como justificar que a legitimidade da autoridade ou das instituições está nas regras jurídicas que a confere se essas regras só podem conferir legitimidade se elas já a tem? (DWORKIN, 1999).

A resposta a essas indagações é dada pela teoria do direito como integridade, a qual reputa que:

Segundo o direito como integridade, as proposições jurídicas são verdadeiras se constam, ou se derivam, dos princípios de justiça, equidade e devido processo legal que oferecem a melhor interpretação construtiva da prática jurídica da comunidade. (DWORKIN, 1999, p. 272).

O trecho, embora sintético, abrange diversas terminologias que remetem ao particular esquema teórico dworkiniano, pois considerar 'proposições jurídicas verdadeiras' está associado à proposta de justificação moral das assertivas jurídicas. $\mathrm{O}$ termo 'princípio' refere-se a uma concepção específica de se produzir, interpretar e aplicar normas jurídicas a partir de esquemas de responsabilidades e justificações morais mais amplos. As noções de 'justiça e equidade' concernem a sua teoria de justiça baseada na unidade de valor. A 'melhor interpretação construtiva' é uma referência específica à teoria da única resposta correta, à epistemologia abrangente e à metodologia linguístico-interpretativa do direito. E, por fim, o termo

\footnotetext{
${ }^{3}$ Cuja legitimidade se baseia na noção de autoridade, vez que se considera legítimo o direito dito/decidido por aquele que é reconhecido pela comunidade para decidir. Podem ser consideradas representativas dessa noção de legitimidade as propostas teóricas de Austin e a de Hart, esta especificamente no ponto em que ele justifica a validade da sua norma de reconhecimento. (MACEDO JÚNIOR, 2013).

${ }^{4}$ Também inclui argumentações que justificam a existência de deveres/obrigações oriundas da auto-identificação com o semelhante, a partir da consciência de haver traços pscico-biológicos em comum. A filosofia de Kant seria um destes exemplos. (MACEDO JÚNIOR, 2013).
}

Rev. De Teorias Da Justiça, Da Decisão E Da Argumentação Jurídica | e-ISSN: 2525-9644| Goiânia| v. 5 | n. 1 | p. 39- 
'comunidade' não é empregado no sentido que se dá no senso-comum, mas naquele que o autor estrutura a sua comunidade de princípios. Componentes que serão explicitados nas subseções abaixo.

\subsection{Verdade de proposições jurídicas}

Para Macedo Júnior (2013) e Furquim (2010) a teoria do direito como integridade é apreensível somente a partir da identificação do seu conteúdo epistemológico - que exige interpretar as proposições jurídicas ${ }^{5}$ levando a sério todas as disciplinas e saberes que dizem respeito a prática jurídica ${ }^{6}$ - e do seu conteúdo metodológico proposto a superar os postulados do positivismo-jurídico, substituindo a descrição neutra da norma de direito pela interpretação construtiva e valorativa ${ }^{7}$ da prática jurídica, e substituindo a filosofia da consciência para realizar o giro linguístico ${ }^{8}$.

Explique-se: o conteúdo epistemológico de Dworkin implica que o conhecimento jurídico seja produzido integrando e suprimindo os limites entre os níveis da técnica-ciênciateoria ${ }^{9}$, bem como, fazendo comunicar, na interpretação do significado das proposições jurídicas, as diferentes disciplinas/ciências do conhecimento sobre direito, culminando numa abordagem epistemológica bastante distinta da positivista, na qual o conhecimento sobre direito desenvolve-se compartimentado em ciências/disciplinas distintas (sociologia, direito, filosofia, economia, psicologia etc) e por temáticas também separadas (teoria política, teoria ética, teoria

\footnotetext{
${ }^{5}$ A expressão 'proposições jurídicas' é utilizada com o propósito específico de incluir no âmbito do que é jurídico todo enunciado sobre o que é o direito, mesmo que esse enunciado não tenha natureza de regra ou princípio. Por isso, não se pode considerar proposição jurídica sinônimo de norma jurídica. Pois, Dworkin não concebe o direito a partir de um número fixo de padrões, alguns dos quais são regras e outros, princípios. Mas se opõe à ideia de que o direito é um conjunto fixo de padrões de algum tipo. (DWORKIN, 2010, p. 119).

${ }^{6} \mathrm{O}$ termo 'prática jurídica' é empregado com a finalidade específica de afastar as abordagens metodológicas que Dworkin rejeita: o positivismo jurídico e o sociológico. Logo, o termo se refere a considerar como objeto do direito a ação humana que se constitui, se define, e se torna apreensível e jurídica interpretativamente: a prática jurídica. (MACEDO JÚNIOR, 2013).

${ }^{7}$ Não no sentido de se atribuir opções ideológicas, mas no sentido veritativo, de se atribuir valor de falso ou verdadeiro. Também não se refere a falso ou verdadeiro a partir de opções pessoais, pois a sua teoria trata de apresentar condições de objetividade desta atitude valorativa. (FURQUIM, 2010).

${ }^{8} \mathrm{O}$ giro linguístico, linguistc turn, pode ser entendido como uma abordagem filosófica de produção do conhecimento que considera o ser, o pensar e a razão humana, antes, linguagem, e, por isso, leva em conta os influxos das teorias de linguagem sobre a própria metodologia do saber que se aborda. Nesse sentido, Furquim (2010), Macedo Júnior 2013 e Pedron (2013).

${ }^{9} \mathrm{O}$ conhecimento jurídico desenvolve-se sob três secções epistêmicas: a técnica, que estabelece procedimentos conjugados e bem orientados para produzir resultados úteis; a ciência, onde o saber é organizado a partir da verificação dos níveis de desempenho e do esclarecimento da técnica; e a teoria-científica, na qual se realiza a estruturação dos protocolos desenvolvidos na ciência sob perspectiva eminentemente filosófica (LEAL, 2018). Ressalve-se que, embora o autor aponte três níveis, a proposta de sua teoria é acrescentar um quarto nível, a crítica-científica, que não foi considerada nesse trabalho, ante a inovação específica do autor.
}

Rev. De Teorias Da Justiça, Da Decisão E Da Argumentação Jurídica | e-ISSN: 2525-9644| Goiânia| v. 5 | n. 1 | p. 39- 
jurídica). Dworkin assim defende uma epistemologia 'abrangente' ${ }^{10}$. (MACEDO JÚNIOR, 2013).

Quanto ao conteúdo metodológico dworkiniano, Macedo Júnior (2013), Pedron (2013) e Brina (2016) explicam que Hart colocou no debate contemporâneo a discussão sobre a dimensão interna da regra, onde se situam as 'razões de agir', e refutou a compreensão positivista (de Austin, Kelsen e Bentham) que a regra jurídica, objeto de estudo da ciência jurídica, teria apenas uma dimensão externa, observável e descritível. A partir disso, Hart verificou que as razões de agir, além de constituírem a prática normativa, continham uma intencionalidade, não no sentido psiquíco-subjetivo, mas funcional. E embora interno e intencional, poderia ser descrito, pois tinham natureza factual, essas razões de agir eram as normas de reconhecimento, mantendo, nessa perspectiva, a secção entre o direito e moral.

A partir deste ponto, Dworkin aponta a contradição do modelo hartiano, pois, ao considerar a norma de reconhecimento factual, a dimensão interna das normas primárias tornarse-iam também factuais e destituídas de intencionalidade (MACEDO JÚNIOR, 2013). Além disso, Dworkin demonstra que a teoria hartiana permitiria aos juízes utilizarem a discricionariedade para criar regras jurídicas, o que era incoerente ao sistema inglês que negava essa possibilidade. Por fim, Dworkin argumenta que os juízes utilizam, embora declarem o contrário, razões morais particulares para decidir acerca das divergências teóricas ${ }^{11}$ no direito. (PEDRON, 2013).

Então Dworkin busca apresentar uma proposta que forneça objetividade à interpretação e ao trato da moral ${ }^{12}$ : a teoria interpretativista, pela qual o direito exige um tipo de atitude interpretativa que torne a prática jurídica, reconhecida pela interpretação, uma proposição verdadeira em atender uma exigência substancial de política e justiça. (MACEDO JÚNIOR, 2013).

Porém, desta atitude interpretativa poderia resultar concepções colidentes, embora

\footnotetext{
${ }^{10}$ Assim, nesse trabalho, o termo 'abrangente' será empregado no sentido desta integração das secções epistêmicas (técnicaciência-teoria), disciplinares (Filosofia, Direito, Sociologia, Psicologia etc) ou temáticas (teoria de justiça, teoria política, teoria jurídica etc).

${ }^{11}$ A tese das divergências teóricas é desenvolvida com clareza por Dworkin na análise do caso Elmer (Riggs v. Palmer - 1889) e caso Snail Darter (Tennessee Valley Authority v. Hill - 1978). Ver em Dworkin (2005).

${ }^{12}$ A consolidação de sua concepção de moral é feita em 'Justiça para Ouriços', onde esclarece que o conhecimento articula-se pelos distintos domínios da ciência e do valor (este contém o direito, a moralidade e a ética) que exigem metodologias também distintas. O interpretativismo construtivo seria o método aplicável ao trato da moralidade. (DWORKIN, 2012).

Rev. De Teorias Da Justiça, Da Decisão E Da Argumentação Jurídica | e-ISSN: 2525-9644| Goiânia| v. 5 | n. 1 | p. 39-
} 
ambos fossem aptas a satisfazer a exigência de justiça. Para este problema, conforme Cattoni de Oliveira (2009), Dworkin elabora a teoria da única resposta correta que soluciona a controvérsia teórica ao estabelecer que será correta a resposta que simultaneamente satisfizer em maior grau os vetores substanciais de justiça e for mais adequada às práticas jurídicas amplamente compartilhadas, à semelhança de um romance em cadeia escrito e interpretado da maneira que lhe agregue o maior valor.

A partir desses pressupostos epistêmicos e metodológicos, Dworkin assevera que uma prática somente pode ser considerada jurídica se a proposição que a enuncia for considerada verdadeira ao ser submetida ao 'juízo de justificação moral'13. O resultado dessa interpretação apresenta um direito moralmente justificado. (PEDRON, 2013).

Assim, vê-se que o juízo de justificação moral contém a epistemologia dworkiniana ao conectar teoria de justiça, teoria política e teoria de direito, porquanto exige que a justificação moral de uma interpretação satisfaça, ao mesmo tempo, a coerência ao esquema específico e ao esquema geral (DWORKIN, 1999). E contém, também, a sua metodologia ao examinar as possíveis interpretações a partir de uma intencionalidade, não interna e psíquica, mas externa e objetivamente determinável: a concepção de justiça, equidade e integridade. (CATTONI DE OLIVEIRA, 2009).

Percebe-se, desta forma, que a valoração como falsa ou verdadeira da proposição jurídica decorre de um juízo de justificação a partir do reconhecimento de um sistema substancial, o qual, segundo Brina (2016), estaria inserido numa estrutura mais abrangente: a comunidade política (ou de princípios), que convém ser esclarecida.

\subsection{A comunidade política de princípios}

Após tomar a insuperação ${ }^{14}$ das objeções da seção 2, p. 3, Dworkin busca compreender a lógica da estrutura (aqui se insere o método epistemológico Dworkiano de se produzir o conhecimento jurídico pela conjugação do interpretativismo construtivo a partir do giro linguístico, guiado pela sua teoria abrangente de justiça) pela qual se desenvolvem as

\footnotetext{
${ }^{13}$ A partir do reconhecimento de padrões de interpretação (esquema de justificar certa proposição com base em referenciais acerca de justiça, equanimidade e integridade) mais gerais e abstratos, o processo de justificação moral consiste utilizar esquemas mais específicos (princípios) para justificar a interpretação mais adequada de uma prescrição textual que guarde coerência, ao mesmo tempo, com os demais esquemas específicos (princípios morais) e com os esquemas gerais (política moral). (MACEDO JÚNIOR, 2013).

${ }^{14}$ Não no sentido de estarem destituídas de um mínimo qualquer de racionalidade ou no sentido dessas propostas serem completamente falsas, mas no sentido de que há justificativas melhores, mais adequadas, a partir de um exercício comparativo. Rev. De Teorias Da Justiça, Da Decisão E Da Argumentação Jurídica | e-ISSN: 2525-9644| Goiânia| v. 5 | n. 1 | p. 39-
} 
'obrigações fraternais' em uma comunidade básica ${ }^{15}$, isto porque, baseado nesta estrutura específica, ele elaborará, por meio do interpretativismo construtivo, uma estrutura mais genérica que legitime as 'obrigações jurídicas', nas palavras do autor:

Estamos, finalmente, em condições de examinar nossa hipótese de maneira direta: a melhor defesa da legitimidade política - o direito de uma comunidade política de tratar seus membros como tendo obrigações em virtude de decisões coletivas da comunidade - vai ser encontrada não onde os filósofos esperaram encontrá-la, no árido terreno dos contratos, dos deveres de justiça ou das obrigações de jogo limpo [...] mas no campo mais fértil da fraternidade, da comunidade e de suas obrigações concomitantes. (DWORKIN, 1999, p. 249-250, grifo nosso).

Com este objetivo, Dworkin (1999) identifica a existência de circunstâncias e de condições que justificam as responsabilidades morais das obrigações fraternais numa comunidade básica ${ }^{16}$, e descreve como sendo 'circunstâncias': (1) a possibilidade das obrigações perderem seu caráter imperativo, se as prerrogativas de pertencer a esse grupo não forem dadas aos membros; (2) as relações de associação entre os membros da comunidade e as obrigações delas decorrentes não são formadas por um ato de compromisso contratual deliberado; (3) o dever de honrar as responsabilidades de uma comunidade é fundado na noção de reciprocidade $^{17}$ que diz respeito ao reconhecimento mútuo da existência de uma responsabilidade entre os membros, reconhece-se haver uma responsabilidade para com o outro a medida que o outro reconhece tê-la também em relação a outrem.

Para que essas responsabilidades sejam vistas como obrigações fraternais é necessário as seguintes 'condições': (1) responsabilidade especial - que se refere ao caráter diferenciador em relação aos não membros que se atribuiu a responsabilidade; (2) responsabilidade pessoal - relacionada ao nexo direto de consideração entre os membros, o membro imputa a si, antes de imputar ao grupo comunitário, uma responsabilidade direta para com outro membro ${ }^{18}$; (3)

\footnotetext{
${ }^{15}$ Ressalte-se a importância de distinguir comunidade básica de comunidade política (ou de princípios), porquanto não se confundem, embora semelhantes. (DWORKIN, 1999).

${ }^{16}$ Anote-se que Dworkin apresenta três gradações de comunidade: a básica, contendo as quatro condições iniciais; a associativa que incrementa às qualificações da básica o reconhecimento da justiça e a prática interpretativa; e a política. (DWORKIN, 1999).

17 Quanto à instabilidade de se definir o que se pode considerar uma responsabilidade existente, visto que seu conteúdo é interpretativo, Dworkin argumenta que o parâmetro é a 'atitude' de interpretar o conteúdo dessa responsabilidade negando aqueles que o contrarie. As pessoas não precisam concordar com exatidão sobre o que significa 'amizade', mas concordam com um mínimo acerca do que ela não é. (DWORKIN, 1999).

${ }^{18}$ Exemplifica essa condição o fato que alguém vendo uma criança perdida, em vez de ignorar alegando que existem autoridades cujo o papel é justamente cuidar dessa criança e localizar os pais, tem a atitude de pessoalmente prestar esse auxílio, deixando de empregar tempo e esforços em prol dos seus interesses por conta da responsabilidade que ele considera ter diretamente com a criança e não para com a criança perante o grupo.
}

Rev. De Teorias Da Justiça, Da Decisão E Da Argumentação Jurídica | e-ISSN: 2525-9644| Goiânia| v. 5 | n. 1 | p. 39- 
abrangência $^{19}$ - as obrigações fraternais específicas são aplicações contigenciais $^{20}$ de um esquema de responsabilidade mais geral; (4) igualdade - as práticas do grupo que endossam as responsabilidades levam em igual consideração os interesses de todos os membros da comunidade. (DWORKIN, 1999).

A partir das condições existenciais-qualificativas da comunidade básica (responsabilidade especial, responsabilidade pessoal, responsabilidade abrangente e igualdade) Dworkin incluiu na reciprocidade da comunidade básica o atributo do 'reconhecimento de justiça' por meio da 'prática interpretativa'. A comunidade que faz isso ganha o status de associativa, representada esquematicamente na Figura 1.

Figura 1 - Desenho esquemático da comunidade fraternal

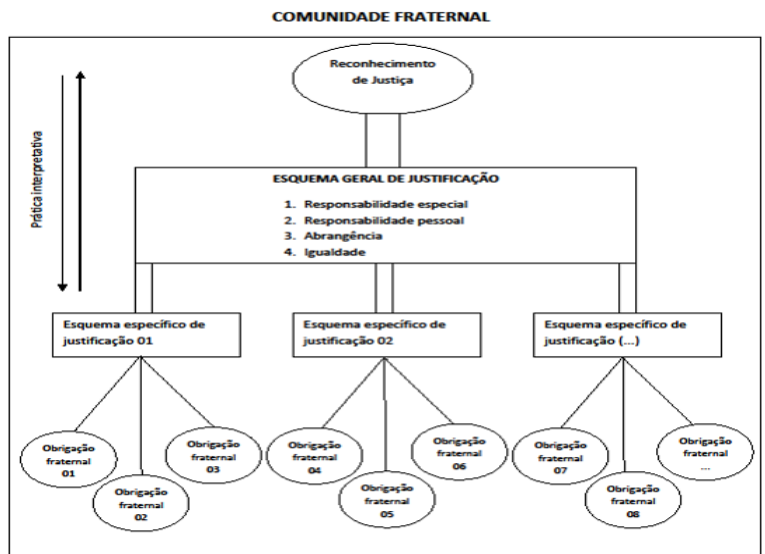

Fonte: próprio autor

E é a partir dessa comunidade associativa que Dworkin buscará legitimar a obrigação jurídica, ao dizer que: "Esse eco reforça nossa hipótese corrente de que a obrigação política inclusive a obrigação de obedecer ao direito - é uma forma de obrigação associativa". (DWORKIN, 1999, p. 249, grifo nosso).

Partindo disso, verifica-se que, em analogia à lógica-estruturante que legitima uma obrigação fraternal, Dworkin elabora uma estrutura mais genérica e politizada que legitime uma obrigação jurídica, veja-se:

\footnotetext{
${ }^{19}$ Essa derivação é a alternativa de Dworkin para resolver divergências teóricas no nível pré-interpretativo, pois havendo estruturas de justificação específicas (princípios) que legitimem responsabilidades/obrigações colidentes, a existência de um esquema mais profundo e genérico de justificação amortecerá o conflito e manterá a integridade de todo o sistema.

${ }^{20}$ Contingente porque se refere a um tempo específico, a uma hipótese fática, num determinado tempo, e num determinado ato interpretativo. Claro que não se quer dizer instável e aleatório, mas que não também não seja um dogma.
}

Rev. De Teorias Da Justiça, Da Decisão E Da Argumentação Jurídica | e-ISSN: 2525-9644| Goiânia| v. 5 | n. 1 | p. 39- 
Dediquei uma atenção tão especial à estrutura da obrigação associativa e à natureza e circunstâncias de seus conflitos com outras responsabilidades e direitos, porque meu objetivo é mostrar de que modo a obrigação política pode ser considerada associativa, e isso só será plausível se a estrutura geral das obrigações associativas nos permitir explicar as condições que em nosso ponto de vista, têm de ser satisfeitas antes que se coloque a questão da obrigação política, e as circunstâncias que, acreditamos, devem invalidá-la ou mostrá-la em conflito com outros tipos de obrigações. (DWORKIN, 1999, p. 248-249).

Após identificar as quatro condições, retrocitadas, que definem a 'comunidade associativa', Dworkin (1999, p. 251) indaga: "Que forma deveriam assumir em uma comunidade política? Como deve ser a política para que uma sociedade política básica possa tornar-se uma verdadeira forma de associação fraternal?".

As respostas vão sendo elaboradas em seguida, iniciando-se pela incrementação dos atributos da reciprocidade da comunidade associativa com o atributo de que "a comunidade deve respeitar princípios necessários à justificação de uma parte do direito, bem como do todo." (DWORKIN, 1999, p. 254), assumindo, assim, a reciprocidade primitiva da comunidade básica uma proposta de modelo geral de associação na comunidade política.

Na comunidade política, ver no item 3 da Figura 2, a responsabilidade especial tornase responsabilidade 'específica de cidadania', significando que:

Cada cidadão respeita os princípios do sentimento de equidade e de justiça da organização política vigentes em sua comunidade particular, que podem ser diferentes daqueles de outras comunidades, considere ele ou não que, de um ponto de vista utópico, são esses os melhores princípios. (DWORKIN, 1999, p. 257).

A responsabilidade pessoal também é incrementada e passa a corresponder a exigência de que:

[...] ninguém seja excluído; determina que na política, estamos todos juntos para o melhor ou pior [...] que ninguém pode ser sacrificado [...] pela justiça total. [o interesse pelo outro] Manifesta-se assim [na política que o inicia] e é mantido pela legislação que rege a prestação jurisdicional e sua aplicação. Os atos políticos de todos exprimem sempre, ao se mostrar como devem ser as regras e de que modo se devem aplicá-las, um profundo e constante compromisso que exige sacrifício, não apenas por parte dos perdedores, mas também dos poderosos que teriam a ganhar como tipo de conluio e soluções conciliatórias que a integridade proíbe. (DWORKIN, 1999, p. 257, acréscimos nosso)

No item (3) da Figura 2, vê-se que se acresce à condição 'igualdade' o atributo integridade, passando a ser compreendida como o pressuposto que cada cidadão é tão digno quanto qualquer outro, que cada um deva ser tratado com o mesmo interesse, "de acordo com

Rev. De Teorias Da Justiça, Da Decisão E Da Argumentação Jurídica | e-ISSN: 2525-9644| Goiânia| v. 5 | n. 1 | p. 39- 
uma concepção coerente do que isso significa.". (DWORKIN, 1999, p. 257).

Encerrando as transposições conceituais, na comunidade política, conforme item (2) da Figura 2, a noção de justiça ${ }^{21}$ é incrementada pela noção de equidade ${ }^{22}$, devido processo legal adjetivo, num esquema onde justiça e equidade são equalizados pela integridade. (DWORKIN, 1999). Por fim, quanto aos 'princípios', no esquema conceitual da Figura 2, abaixo, pode-se compreender de maneira mais exata a que ele remete, uma vez que sua significação exige levar em conta, de maneira abrangente, a sua relação com as obrigações, as responsabilidades, e os esquemas de justificação, conforme explicitado no próximo tópico.

\subsection{Os verdadeiros princípios de Dworkin}

Geralmente, o que tem levado a propagação do pensamento de Dworkin no meio acadêmico é a importância de se incorporar princípios jurídicos e morais no Direito, porém essa discussão é bastante anterior às suas obras. Por isso, a originalidade da teoria de Dworkin não reside na valorização dos princípios ou na oposição entre regras e princípios, mas, sim, na sua proposta metodológica referida pelos princípios morais. (MACEDO JÚNIOR, 2013).

É comum compreender princípio como juízo de adequação, mandado de otimização, normas fundamentais de um sistema, ou vetor de interpretação e conciliação das regras jurídicas (SILVA, 2003). No entanto, os princípios morais a que Dworkin se refere é a estrutura metodológica, que está abrangida pelo esquema geral do direito como integridade, de atribuir verdade ou falsidade às proposições jurídicas. No item (4) da Figura abaixo pode-se identificar graficamente ao que se refere o princípio moral dworkiniano, onde corresponderia ao esquemas específicos de justificações na comunidade associativa na Figura 1 retromencionada.

Figura 2 - Desenho esquemático da comunidade política

\footnotetext{
${ }^{21}$ Que funciona como a diretriz ideológica da estrutura procedimental formada pelas relações entre as condições de responsabilidade, de abrangência e de igualdade.

22 Pedron sustenta que a melhor tradução do termo fairness não seria equidade, mas 'equanimidade' que "envolve a questão de encontrar os procedimentos políticos que distribuem o poder político de maneira adequada". (PEDRON, 2013, p. 48).

Rev. De Teorias Da Justiça, Da Decisão E Da Argumentação Jurídica | e-ISSN: 2525-9644| Goiânia| v. 5 | n. 1 | p. 39-
} 


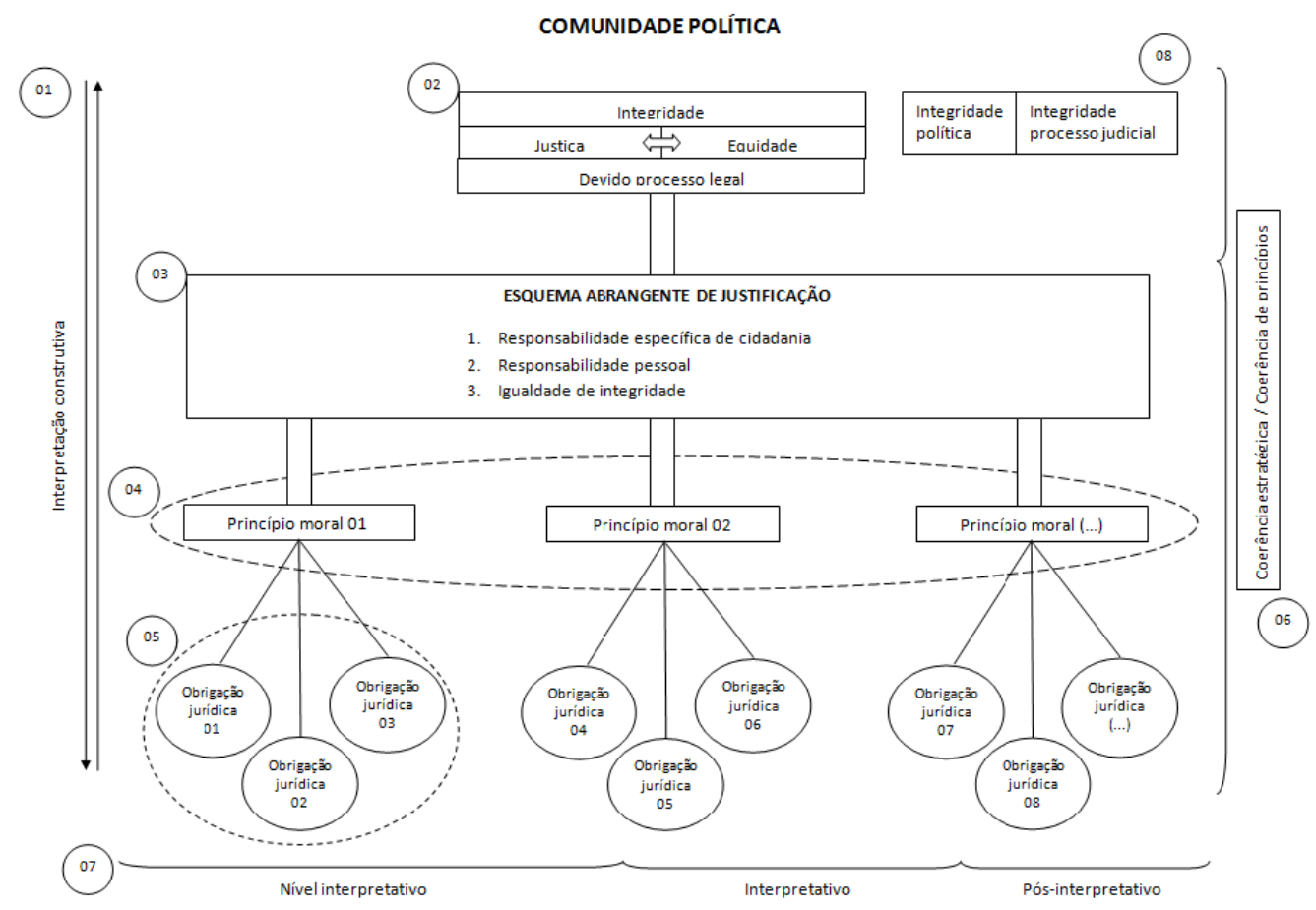

Fonte: próprio autor

Essa noção de princípio, simultaneamente procedimental e substancial, é referida por Dworkin ao estruturar o modelo geral de associação da comunidade política, ao apresentar a teoria do direito como integridade e ao distinguir a integridade na política e no processo judicial (DWORKIN, 1999). Também é referida ao distinguir argumentos de princípios e de política (DWORKIN, 2010). O autor inclusive utiliza esse conceito de princípio para elaborar sua concepção de Estado de Direito, descrita no primeiro capítulo de 'Uma questão de princípios' (DWORKIN, 2005). Veja-se a descrição de princípio abaixo:

\footnotetext{
Um argumento de princípio pode oferecer uma justificação para uma decisão particular, segundo a doutrina da responsabilidade, somente se for possível mostrar que o princípio citado é compatível com decisões anteriores que não foram refeitas, e com decisões que a instituição está preparada para tomar em circunstâncias hipotéticas. (DWORKIN, 2010, p. 138).
}

Percebe-se que, embora o argumento se refira à distinção entre argumento de política e de princípio, os elementos citados no texto tem correspondência na estrutura esquematizada da Figura 02, já que a 'doutrina de responsabilidade' está representada no item (3), a 'decisão particular' corresponderia a obrigação reconhecida como jurídica do item (5). Ademais, há que se considerar que o esquema é aplicável tanto ao processo judicial quanto ao legislativo,

Rev. De Teorias Da Justiça, Da Decisão E Da Argumentação Jurídica | e-ISSN: 2525-9644| Goiânia| v. 5 | n. 1 | p. 39- 
conforme item (8). Assim o esquema institucional hipotético para produzir decisões corresponderia a essa estrutura abrangente da Figura 2.

\subsection{Justiça, equidade e devido processo legal}

A partir da Figura 2, nota-se que 'justiça' é um dos elementos de substância que contém a opção política da estrutura procedimental-metodológica da teoria do direito como integridade apresentada nesta pesquisa a partir de 'O Império do Direito', cuja primeira publicação data de 1986. Porém a noção de justiça dworkiniana foi aprimorada na teoria da unidade do valor, apresentada em 2011, quando, segundo Brina (2016), o autor desenvolveu uma teoria abrangente de justiça.

Logo, há que se compreender o direito como integridade a partir dessa nova concepção de justiça, pois, embora seja uma noção posterior, percebe-se que desde 1986 Dworkin indicava a unidade e abrangência da justiça, ao dizer que a coerência de princípio "Exige que os diversos padrões que regem o uso estatal da coerção contra os cidadãos seja coerente no sentido de expressarem uma visão única e abrangente de justiça" (1999, p. 163, grifo nosso).

Brina (2016) explica que Dworkin, desenvolvendo a concepção de justiça na teoria da unidade do valor, apresentou parâmetros específicos - entre eles o sistema de responsabilidade objetiva - aptos a fornecer objetividade ${ }^{23}$ à moralidade ${ }^{24}$ tão referida na sua obra, uma vez que autor, não obstante compreender direito e moral num mesmo domínio, concebe uma moral institucionalizada, não relacionada às vicissitudes pessoais, visto que Dworkin rejeita concepções da metafísica e da noção fisicalista ${ }^{25}$ do direito.

Assim, a moral deve ser compreendida levando em conta os mecanismos contidos na teoria da unidade de valor. Diz-se unidade de valor porque propõe a continuidade ${ }^{26}$ entre a moral individual - tomada por Dworkin como ética - e a moral da comunidade de princípios, que, consideradas conjuntamente, são designadas por 'moralidade', nas palavras de Furquim

\footnotetext{
${ }^{23}$ Ou na expressão de Macedo Júnior (2013) 'condições para existência de objetividade' no âmbito das divergências teóricas acerca da proposição jurídicas.

${ }^{24} \mathrm{~A}$ 'moralidade' aqui deve ser considerada no âmbito da Teoria da Unidade de Valor que abrange a integralização (no sentido de tomar com um corpo único) a moral (noção do que é adequado para a coletividade) e ética (noção do que é a vida boa individualmente individual), pois em 'Justiça para Ouriços' Dworkin conceberá o Direito como um ramo da moralidade política. (BRINA, 2016).

${ }^{25}$ Terminologia proposta por Macedo Júnior (2013) que compreende as teorias do direito derivadas das epistemologias empiristas e racionalistas.

${ }^{26}$ Como Furquim (2010, p. 20) sintetiza "o que desejamos para as nossas vidas não pode estar separado de como devemos tratar os outros".
}

Rev. De Teorias Da Justiça, Da Decisão E Da Argumentação Jurídica | e-ISSN: 2525-9644| Goiânia| v. 5 | n. 1 | p. 39- 
(2010, p. 20):

Para Dworkin, a continuidade não requer que as pessoas definam sua vida em torno da imparcialidade ou da busca pela justiça, mas requer que a discussão pública ressoe nas convicções sobre as nossas concepções de boa vida. É uma ideia de unidade de valor entre a ética e a moralidade que ainda está em construção. Para Guest (2007), a ética pessoal de todos participando desse consenso, mas sem recair numa perspectiva pessoal específica, é o apelo visionário de Dworkin, alternativo ao contrato, para sua versão contínua do liberalismo - a igualdade liberal. (FURQUIM, 2010, p. 20).

Furquim explica que a legitimidade da coerção estatal - chamada pela autora de 'força categórica do Direito' e que é uma justificação moral - estaria na união da ética ${ }^{27}$ com a moralidade por meio de uma abordagem interpretativa; e que o termo 'valor' na teoria de justiça refere-a utilidade prática (factual) que a compreensão unificada de justiça e equidade enseja para a interpretação das práticas jurídicas, veja-se:

\begin{abstract}
A proposta de Dworkin é que não podemos tratar valores políticos como separados do que consideramos a boa vida. A liberdade, justiça, igualdade, democracia têm valor por causa das consequências para as nossas vidas. Considerar valores políticos separados do que é a vida boa leva-nos a um conflito entre liberdade e igualdade. (FURQUIM, 2010, p. 28).
\end{abstract}

Assim, uma vez que os conceitos de justiça, liberdade e igualdade são argumentativointerpretativos e não descritivos, visto não poderem ser tomados como um objeto natural ou factual, ante sua inexistência física (MACEDO JÚNIOR, 2013). Furquim (2010) sugere que o conceito de justiça interessa à prática jurídica por conter um valor - uma funcionalidade - que decorra não apenas de uma idealidade - por exemplo, pensar que se deve buscar a justiça porque a justiça é boa - mas que decorra das consequências práticas que essa noção de justiça ensejará na vida de cada um.

Ressalve-se que a compreensão de justiça a partir da teoria da unidade de valor implica compreender o complexo esquema apresentado em 'Justiça para ouriços' sobre igualdade, liberdade, democracia, Direito e sistema de responsabilidade objetiva, temas que extrapolam o limite do artigo. Porém, essa limitada remissão à teoria, que aponta para um conceito não utópico de justiça, mas funcional, será útil no desenvolvimento da seção 3.

Quanto ao significado de equidade, Furquim (2010) esclarece que, a partir do

\footnotetext{
${ }^{27}$ Dworkin quando fala de moralidade refere-se à moralidade pública de como devemos tratar os outros e ética a moralidade pessoal. Furquim (2010, p. 16)

Rev. De Teorias Da Justiça, Da Decisão E Da Argumentação Jurídica | e-ISSN: 2525-9644| Goiânia| v. 5 | n. 1 | p. 39- 
pressuposto de que todo cidadão merece igual consideração, equal concern, e que todos temos responsabilidades especiais entre si, a equidade diz respeito a conceber uma estrutura política cuja o processo legislativo e judicial resultem na distribuição adequada dos recursos de uma nação. Nesse sentido, Dworkin diz que:

Se aceitarmos a justiça como uma virtude política, queremos que nossos legisladores e outras autoridades distribuam recursos materiais e protejam as liberdades civis de modo a garantir um resultado moralmente justificável. (DWORKIN, 1999, p. 200).

No item (2) da Figura 2, justiça e equidade, embora interrelacionados, possuem existência autônoma e estão equalizados pela integridade, significando que, conforme Dworkin (1999), numa sociedade não utópica as circunstâncias factuais podem fazer conflitar aplicações decorrentes da noção de justiça com da noção de igualdade ${ }^{28}$, situação que será solucionada pela integridade do processo judicial, do processo legislativo e da política:

\footnotetext{
[em relação ao processo judicial] a comunidade deve respeitar princípios necessários à justificação de uma parte do direito, bem como do todo[...] [em relação ao processo legislativo] que pede aos que criam o direito por legislação que o mantenham coerente quanto aos princípios [...] [integridade política] quando insistimos em que o Estado aja segundo um conjunto único e coerente de princípios mesmo quando seus cidadãos estão divididos quanto à natureza exata dos princípios de justiça e equidade corretos. (DWORKIN, p. 202-203, 254, acréscimos nosso).
}

Após estas considerações, acredita-se que os principais elementos da teoria do direito como integridade, referidos no conceito da p. 3, foram apresentados e são suficientes para abordar a crítica da teoria neoinstitucionalista do processo.

\section{A CRÍTICA NEOINSTITUCIONALISTA}

A teoria neoinstitucionalista é uma concepção específica de processo elaborada por Leal (2018) que apresenta agudas críticas às noções teóricas de Ronald Dworkin sobre o processo judicial. Assim, antes de apresentá-las, é necessário compreender 'o que é o direito' na perspectiva neoinstitucionalista, veja-se:

É o direito produto racional e dinâmico de controle sociopolítico-econômico em vários níveis temporais de elaboração humano-técnica, à medida que os grupos sociais surgem, organizando-se a si mesmos por regramentos técnicos-jurídicos convenientes. (LEAL, 2018, p. 19)

\footnotetext{
${ }^{28}$ A exemplo da análise do caso Bakke em (DWORKIN, 2005) e do caso hipotético do casamento forçado em (DWORKIN, 1999, p. 244-249).

Rev. De Teorias Da Justiça, Da Decisão E Da Argumentação Jurídica | e-ISSN: 2525-9644| Goiânia| v. 5 | n. 1 | p. 39- 
Os vocábulos deste trecho contém significações complexas e importantes a compreensão do conceito de direito para o autor, a exemplo da palavra 'controle' que, conforme Leal (2018) não se refere a um controle das estruturas sociais a partir dos interesses predominantes num determinado tempo-local-histórico (nos termos da proposta de Gustav e Savigny) mas do controle da miserabilidade e das disfunções da sociedade e da economia.

A expressão 'a medida que os grupos sociais surgem' reflete a provisoriedade da validade do conhecimento jurídico que está sempre sujeito à testificação e superação, implicando-se, assim, afastar a concepção jusnaturalista de afirmar a existência de conhecimentos jurídicos atemporais e universais dessumidos da razão e da natureza das coisas. (LEAL, 2018).

Além do conceito acima, a teoria apresenta o objeto imediato e mediato da ciência jurídica (que contém a proposta metodológica de produção jurídica) nos seguintes termos:

[...] objeto imediato, que é produzir conhecimentos explicativos, pela crítica do conhecimento, de sua própria validade discursiva e, servindo-se dessa produção científica, promover, como objeto mediato, a investigação do conteúdo ou sentido do direito expresso pelo complexo de normas resultantes da existência jurídica articulada com o modo de produção das relações econômicas e sociais vigorantes. (LEAL, 2018, p. 26-27, destaque do próprio autor).

Percebe-se nestes trechos a relevância do vetor 'economia' e da cautela de se 'validar' tanto a discursividade produtora do conhecimento jurídico quanto as próprias proposições jurídicas ao inserir no conceito de direito, exposto na p. 13, que os regramentos técnicosjurídicos deveriam ser 'convenientes' ao propósito sócio-econômico. A discursividade jurídica, de acordo com a teoria neoinstitucionalista, é validada pela metodologia de Karl Popper; e os regramentos são validados pelo elemento procedimental do processo e pelo elemento político de equalização da desigualdade econômica social (LEAL, 2018).

Enfatiza-se essas duas questões porque, como visto na seção 2, Ronald Dworkin expressamente leva em conta na estrutura do direito como integridade o vetor econômico, visto que a equidade instituiu a necessidade do direito ser compreendido como equalizador da desigualdade para que ocorra a distribuição dos recursos econômicos da nação. Ademais, tal como Leal enseja submeter à validação tanto os níveis de produção do conhecimento jurídico, o direito produzido, Dworkin também propõe a justificação do direito desde o nível pósinterpretativo ao pré-interpretativo das proposições jurídicas deles decorrentes.

Rev. De Teorias Da Justiça, Da Decisão E Da Argumentação Jurídica | e-ISSN: 2525-9644| Goiânia| v. 5 | n. 1 | p. 39- 
Além dessas proposições, Leal apresenta alguns atributos que não corresponderiam ao seu conceito de direito:

O direito não é um ente que tenha princípios e critérios congênitos, intrínsecos e messiânicos, emergidos por geração espontânea, que vincassem a humanidade, inculcando, de modo apostolar, o justo ou o equitativo como cânone milagroso e instrumental de pacificação da sociedade, instilável pelo suposto senso inato dos juízes, como queriam os adeptos da Escola Alemã do Direito Livre (Freirecht). (LEAL, 2018, p. 22, destaques do próprio autor).

Infere-se, a partir do trecho acima e das outras críticas ${ }^{29}$ a Dworkin ao longo da obra de Leal, que a teoria neoinstitucionalista atribui a concepção do direito como uma entidade que contém princípios que desvelam o justo e o equitativo pela batuta do juiz à teoria dworkiniana do direito como integridade. No entanto, esta atribuição há que ser melhor esclarecerida, pois o termo Freirecht refere-se à escola histórica do direito, a qual, podendo ser representada por Kantorowicz e Gény, postulava que, em casos excepcionais, o juiz poderia decidir contra legem ou praeter legem quando a lei fosse obviamente injusta, baseando-se, para tanto na observação dos dados sociológicos ou no foro íntimo (LARENZ, 2010).

Logo, verifica-se impróprio alinhar Dworkin a Escola do Direito Livre, já que, conforme Macedo Júnior (2013), antes mesmo de Dworkin, Hart, na crítica dirigida a Alf Ross, já refutava compreender o direito a partir de elementos psíquicos, quiçá, de foro íntimo.

Além disso, atribuir a Dworkin a concepção do direito como um 'ente' é problemático, porquanto o conceito dworkiniano parte, conforme Dworkin (2010), de uma atitude interpretativa a partir de uma intencionalidade e, também, de refutação do direito como descrição factual. Ademais, o autor, consoante Dworkin (1999), expressamente afasta do direito como integridade noções de corporificação do direito (replicar estruturas orgânicas às estruturas jurídicas) ao explicar o conceito de comunidade política.

Outro ponto problemático da crítica neoinstitucionalista a Dworkin, é compreendê-lo como defensor de um processo judicial que permita ao juiz, legitimado por uma autoridade inata, alta discricionariedade para, manipulando princípios, decidir o que é o direito a seu belprazer, na assertiva ${ }^{30}$ de Leal (2018, p. 163) "[...] o que se otimiza é a talentosa liberdade que se concede ao feitor e aplicador da lei em seus solitários saberes emersos de ideais universais ou colegiadamente pragmatizados (atividades jurisdicionais) aos moldes de Rawls e Dworkin".

\footnotetext{
${ }^{29}$ Ver Leal (2018) nas páginas 40, 84, 86, 87, 104 e 163.

${ }^{30}$ Crítica neste mesmo sentido, na p. 40, 87 e 104. Rev. De Teorias Da Justiça, Da Decisão E Da Argumentação Jurídica | e-ISSN: 2525-9644| Goiânia| v. 5 | n. 1 | p. 3958 | Jan/Jun. 2019
} 
A questão da discricionariedade é justamente uma das principais críticas de Dworkin ao modelo de Hart que, inclusive, tenta refutá-la no seu pós-escrito a Dworkin:

[...] o direito é, nesses casos fundamentalmente incompleto: não oferece nenhuma resposta aos problemas em pauta. Estes não são regulamentados juridicamente; e, para chegarem a uma decisão em tais casos, os tribunais precisam exercem a função legislativa limitada que denomino 'discricionariedade'. Dworkin rejeita a ideia de que a lei possa ser assim incompleta, deixando as lacunas a serem preenchidas pelo exercício dessa discricionariedade criativa. (HART, 2012, p. 325-326. Grifo nosso).

Essa perspectiva é endossada por Brina (2016), Macedo Júnior (2013) e Pedron (2013) que explicam ter Dworkin rejeitado o 'convencionalismo jurídico' por, entre outras razões, permitir o juiz criar regras jurídicas discricionariamente, acarretando a aplicação retroativa do direito; e rejeitado, também, o 'pragmatismo jurídico' por negar que o juiz possa fazer uma leitura das fontes sociais para decidir e por negar, em casos específicos, os direitos que as pessoas têm. Quanto a legitimidade com base apenas na autoridade, Dworkin ${ }^{31}$ refuta Austin e Hart exatamente pela petição de princípio do argumento de autoridade inata.

Talvez, a razão desta e outras crítica a Dworkin esteja relacionada a incompreensão do significado de valor, princípio e moral na teoria do direito como integridade. Pois o termo 'valor', como viu-se anteriormente, não corresponde a um conjunto de preferências morais, porquanto 'valor' é tomado no sentido veritativo: valor de falso ou verdadeiro que remete aos juízos de justificação morais.

Quanto ao termo 'moral', no senso comum, significaria uma preferência particular sobre certo fato, escolha ou decisão, na dogmática, geralmente, moral refere-se a juízos que as pessoas fazem, acerca de determinado assunto, sobre certo ou erro, justo ou injusto, melhor ou pior.

O conceito de moralidade para Dworkin é mais complexo e diz respeito a considerar os juízos de justificações, que valoram as proposição jurídicas em verdadeiro ou falso, a partir não da experiência (conjuntos de vivências do indivíduo) do juiz, mas a partir da compreensão que os juízos de justificação de um direito (obrigação jurídica) decorrem de uma estrutura ${ }^{32}$ abrangente de responsabilidades, obrigações e noção de justiça e igualdade, compartilhada pela

\footnotetext{
${ }^{31}$ Retomar p. 3 deste trabalho.

${ }^{32}$ Remissão a Figura 2 da p. 10.
}

Rev. De Teorias Da Justiça, Da Decisão E Da Argumentação Jurídica | e-ISSN: 2525-9644| Goiânia| v. 5 | n. 1 | p. 39- 
'comunidade de princípios'.

Essa comunidade compartilha princípios e não 'valores' no sentido sociológico, a comunidade de princípio não correspondente às opções político-ideológicas compartilhadas por uma maioria numérica de indivíduos.

Exemplificando-se o que não é a comunidade de princípios, imagine-se uma pesquisa empírica concluindo que $70 \%$ da população é contra o aborto, $60 \%$ é tolerável à corrupção no setor público, 90 \% é tolerável à sonegação de impostos, e 75\% é a favor da permissão do porte de arma e criminalização do uso de substâncias entorpecentes. A partir do positivismosociológico, esse conjunto de preferências poderia ser denominado princípios compartilhados pela comunidade.

Não é a essa idéia que Dworkin se refere, a comunidade de princípios ${ }^{33}$ refere-se a um sistema de reciprocidade de responsabilidades entre os membros e entre os membros e os princípios da comunidade. Esses princípios são, na verdade, o conjunto de estruturas abstratas (propostas metodológicas ou parâmetros) para se realizar os juízos de justificação morais e não um conjunto de juízos prontos. Nesse sentido:

\begin{abstract}
Os juízes não podem dizer que a Constituição expressa suas próprias convicções. Não podem pensar que os dispositivos morais abstratos expressam um juízo moral particular qualquer, por mais que esse juízo lhes pareça correto, a menos que tal juízo seja coerente, em princípio, com o desenho estrutural da Constituição como um todo e também com a linha de interpretação constitucional predominantemente seguida por outros juízes no passado (DWORKIN, 2006, p. 15).
\end{abstract}

Assim, verifica-se que o devido processo legal da teoria do direito como integridade não corresponde ao que Leal (2018) chama de lei moral dos juízes.

\title{
4 CONSIDERAÇÕES FINAIS
}

O tema-problema da pesquisa girou em torno da crítica da teoria neoinstitucionalista do processo de que a proposta teórica de Ronald Dworkin pressupõe ao juiz discricionariedade para criar regras jurídicas pelo manejo de princípios morais. Uma questão relevante porque a positivação do art. 926 do Código de Processo Civil, referindo-se expressamente à integridade dworkiniana, passou a exigir a compreensão da teoria do direito como integridade.

Ante essas necessidades, na seção 2, apresentaram-se os elementos centrais da

\footnotetext{
${ }^{33}$ Lembrar que 'princípios' remetem aos esquemas de justificação específicos do item (5) da Figura 2, p. 10. Rev. De Teorias Da Justiça, Da Decisão E Da Argumentação Jurídica | e-ISSN: 2525-9644| Goiânia| v. 5 | n. 1 | p. 39-
} 
proposta de Dworkin: a epistemologia abrangente do direito, o método interpretativo construtivo, as concepções de comunidade política, de princípios, equidade, justiça e de integridade, evidenciando-se a preocupação do autor em fornecer parâmetros de objetividade na interpretação da prática jurídica e no trato da moralidade.

Na seção 3 a crítica neoinstitucionalista, mesmo que genericamente, foi explicitada, verificando-se que, embora seja atribuída a Dworkin a permissão teórica para que os juízes discricionariamente interpretem e criem normas, a teoria do direito como integridade expressamente é contrária a essa ideia.

Postas essas reflexões, ressalte-se que a proposta neoinstitucionalista é uma digna e robusta teoria de processo, no entanto, atribuir a Dworkin permissão teórica a discricionariedade judicial é uma questão problemática.

\section{REFERÊNCIAS}

BRASIL. Lei n. 13.105 de 16 de março de 2015. Código de Processo Civil. Diário Oficial [da] República Federativa do Brasil, Brasília, DF, 17 mar. 2015. Disponível em: <http://www.planalto.gov.br/ccivil_03/_Ato2015-2018/2015/Lei/L13105.htm>. Acesso em: 01 nov. 2018.

BRINA, Christina Vilaça. Dworkin e Raz: uma análise comparada sobre o conceito de direito, a relação entre direito e moral, e a interpretação jurídica. 2016. 148 f. Dissertação (Mestrado em Direito), Universidade Federal de Minas Gerais, Belo Horizonte, 2016. Disponível em: < http://www.bibliotecadigital.ufmg.br/dspace/handle/1843/BUOS-ASJFJX>. Acesso em: 23 nov. 2018.

CATTONI DE OLIVEIRA, Marcelo Andrade. Dworkin: de que maneira o direito se assemelha à literatura?.Revista da Faculdade de Direito da UFMG, Belo Horizonte, n. 54, p. 91-118, jan./jun. 2009.

DWORKIN, Ronald. Justiça para ouriços. Tradução de Pedro Elói Duarte. Coimbra: Almedina, 2012.

DWORKIN, Ronald. Levando os direitos a sério. Tradução Nelson Boeira. 3. ed. São Paulo: Martins Fontes, 2010.

DWORKIN, Ronald. O direito da liberdade: a leitura moral da Constituição norte-

Rev. De Teorias Da Justiça, Da Decisão E Da Argumentação Jurídica | e-ISSN: 2525-9644| Goiânia| v. 5 | n. 1 | p. 3958 | Jan/Jun. 2019 
americana. Tradução Marcelo Brandão Cipolla. São Paulo: Martins Fontes, 2006.

DWORKIN, Ronald. O império do direito. Tradução Jefferson Luiz Camargo. São Paulo: Martins Fontes, 1999.

DWORKIN, Ronald. Uma questão de princípio. Tradução Luís Carlos Borges. 2. ed. São Paulo: Martins Fontes, 2005.

FURQUIM, Lilian de Toni. O liberalismo abrangente de Ronald Dworkin. 2010. 235 f. Tese (Doutorado em Ciência Política), Universidade de São Paulo, São Paulo, 2010.

Disponível em: < http://www.teses.usp.br/teses/disponiveis/8/8131/tde-02122010-111403/ptbr.php>. Acesso em: 28 out. 2018.

GUEST, Stephen. Ronald Dworkin. Tradução Luís Carlos Borges. Rio de Janeiro: Elsevier, 2010.

GUSTIN, Miracy B. S.; DIAS, Maria Tereza Fonseca. (Re) Pensando a Pesquisa Jurídica. Belo Horizonte: Del Rey, 2010.

HART, Herbert L. A. O conceito de direito. Tradução de Antônio de Oliveira Sette-Câmara. São Paulo: Martins Fontes, 2012.

LARENZ, Karl. Metodologia do direito. Tradução José Lamego. 6. ed.. Lisboa: Fundação Calouste Gulbenkain, 2010.

LEAL, Rosemiro Pereira. Teoria geral do processo: primeiros estudos. 14. ed. Belo Horizonte: Fórum, 2018. 490 p.

LOPES FILHO, Juraci Mourão. Os precedentes judiciais no constitucionalismo brasileiro contemporâneo. 2. ed. rev. e atual. Salvador: JusPODIVM, 2016.

MACEDO JÚNIOR, Ronaldo Porto. Do xadrez à cortesia: Dworkin e a teoria do direito contemporâneo. São Paulo: Saraiva, 2013. (E-BOOK)

PEDRON, Flávio Quinaud. Em busca da legitimidade do direito contemporâneo: uma análise reconstrutiva das teorias jurídicas de Ronald Dworkin, Jürgen Habermas e Klaus Günther. Belo Horizonte: Clube de Autores, 2013. 201 p.

SILVA, Luís Virgílio Afonso da. Princípios e regras: mitos e equívocos acerca de uma distinção. Revista Latino-Americana de Estudos Constitucionais, Belo Horizonte, n. 1, p. 607-630, jan./jun. 2003. Disponível em: < https://constituicao.direito.usp.br/vaspublicacoes/>. Acesso em: 04 jan. 2019.

THEODORO JÚNIOR, H. et al. Novo CPC: fundamentos e sistematização. 3. ed. rev., atual. e ampl. Rio de Janeiro: Forense, 2016.

Rev. De Teorias Da Justiça, Da Decisão E Da Argumentação Jurídica | e-ISSN: 2525-9644| Goiânia| v. 5 | n. 1 | p. 3958 | Jan/Jun. 2019 